\title{
Realizing and testing a safety registration system to monitor workplace attendances
}

\author{
V. Tonetto, P. Mattei, G. Vassalini \& L. Fornaciari \\ Italian Agricultural Mechanization Research Institute, \\ Via della Pascolare, 16, 00016 Monterotondo, Rome, Italy
}

\begin{abstract}
When an emergency action plan must be executed, workers meet at the safe collecting point. In order to know who is missing, we must be able to determine the workers who are actually present in the workplace. This is a problem of great relevance in the Italian Agricultural Mechanization Institute, where, apart from workers that regularly sign in (and out), a great variety of employees are found daily: temporary employees, scholarship holders, Ph. D. aspirants, outside guests, visitors and maintenance staff that are not scheduled because they don't have an employee timecard. Furthermore the workplace includes offices, laboratories, a machine shop and farm. In this paper we will illustrate and discuss a practical solution for managing of the actual daily attendances on the Institute working premises. Particularly, we are currently testing an IT (Information Technology) Safety Registration System, which allows having an updated workplaces attendance list every two minutes. Thus, when an emergency action plan must be executed, we can save up to a $50 \%$ roll-call time to know who is missing at the collecting point.

Keywords: Safety Registration System, emergency procedures, evacuation exercise, roll-call report, emergency action plan.
\end{abstract}

\section{Introduction}

The Italian Agricultural Mechanization Research Institute (subsequently referred to as I.S.M.A.) was born in the 1967 as a public institute under the supervision of the Ministry of Agricultural and Forestal Policies. It fosters scientific researches in the sector of agricultural mechanization namely: assessing agricultural 
machines' performances, elaborating and carrying out projects for new ones, improving existing machines, operating on agricultural yards and mechanizing agricultural works.

The Institute is placed on an 80 hectares site, including: two main buildings, one where offices are located, and the other with machine shop, laboratories and store. The remaining area consists in experimental fields, plantings, crops and some technical plants to test agricultural tractors.

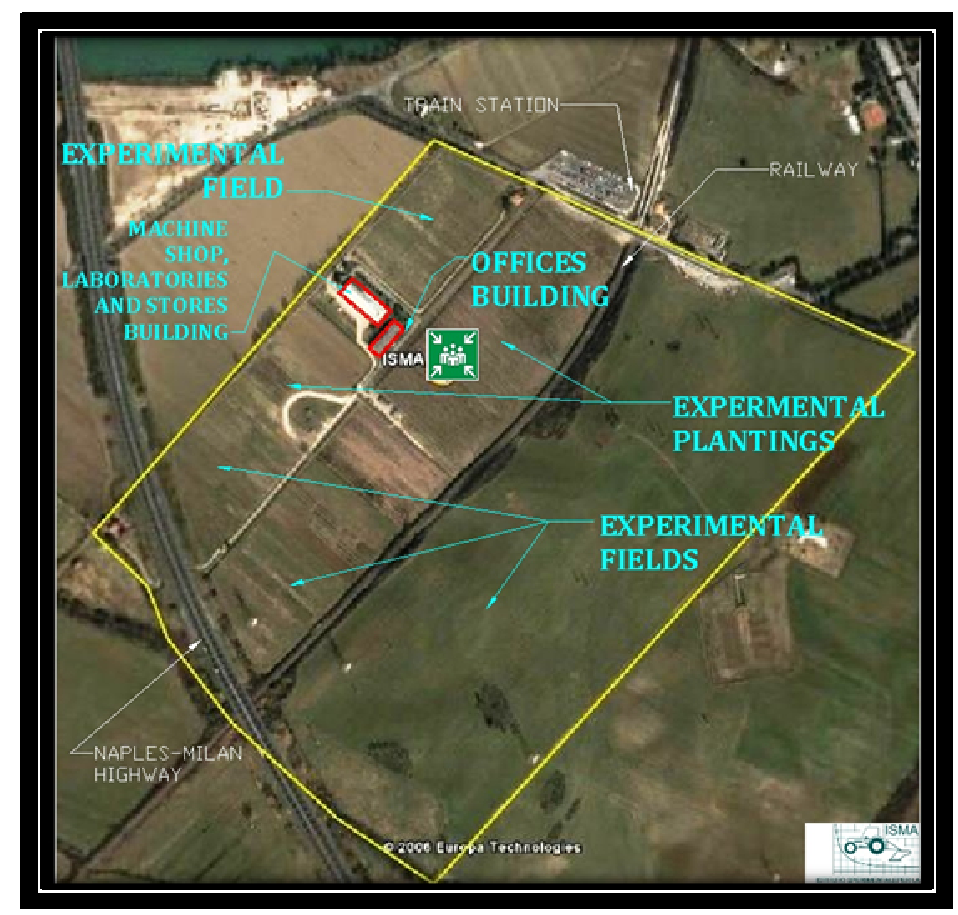

Figure 1: I.S.M.A. area aerial view with highlighted limits in yellow and evacuation meeting location.

The office building has two levels: a ground floor and a first floor. The egresses are three, located completely in the ground floor. The other building has only a ground floor and 7 egresses.

In the office building 22 employees work in the ground floor and 16 employees on the first floor. In the machine shop, laboratories and stores there are habitually 12 workers. Some others few people (as visitors, maintenance staff, carriers) can be in the workplace.

During the working hours, the number of employees actually present in their usual building is very floating, as the I.S.M.A. workplace has got a wide area. For example, when some experimental tests take place in the farm, technical operators, researchers and workers move to the fields. Such a displacement can generate confusion if an emergency takes place at the same time. 


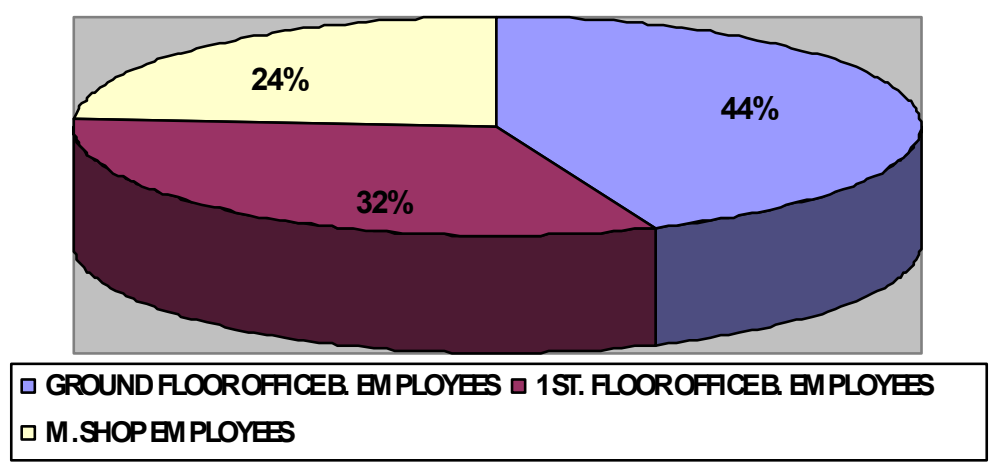

Figure 2: $\quad$ I.S.M.A. employees percentage location.

\subsection{Preliminary remarks}

According to their duty, I.S.M.A. employees can be ordered, as follows:

1. administrative staff;

2. technical operators;

3. researchers;

4. research directors;

5. students (graduating students, Ph.D. aspirants).

Otherwise, with respect to the job contract type, they can be:

a. temporary employees;

b. permanent employees.

The 20 permanent employees have got an employee timecard, where their signing in and out mandatorily registered. On the other hand, temporary employees registered on a hand-written sheet of paper with information about the entrance and exit time, before this Safety Registration System (in the next indicated as S.R.S.) was used. This list was located in the building office hall.

In the case of an evacuation, the switchboard operator was to supply the workplace attendances list to the emergency management staff, as provided by the emergency action plan. This sheet of paper was used to do the roll-call report of presences in the collecting point. The average roll-call report time was about 6 minutes. After this "aid death-time", emergency services started to look for missing people.

Such a system is clearly inefficient for two main reasons: the high probability of getting lost (for example in the case of fire) and because many employees could not have registered out of forgetfulness. Particularly, the employees registered their entrance regularly, but often they forgot to sign their exit.

\section{Italian occupational work safety legislation}

In Italy, the occupational work health and safety is regulated by the legislative decree number 626 of 1994 (directives' actuation 89/391/CEE, 89/654/CEE, 89/655/CEE, 89/656/CEE, 90/269/CEE, 90/270/CEE, 90/394/CEE, 90/679/CEE, 
93/88/CEE, 95/63/CE, 97/42/CE, 98/24/CE, 99/38/CE, 99/92/CE, 2001/45/CE, $2003 / 10 / \mathrm{CE}$ e $2003 / 18 / \mathrm{CE}$ about the improvement of occupational safety and health). The change, compared with the past occupational safety laws, is to place near the traditional layout, founded on compliance with the regulations, carrying out a lasting frame in the workplace to find occupational safety specific risks and the definition of safety measures to improve safety conditions.

The emergency management in the workplace is ruled by the Ministry of the Internal Policies decree 10 March 1998 (Occupational fire safety and emergency management general rules). The fifth article states that the employer, after fire risks valuation, "take the necessary organizational and managerial measures to accomplish in event of fire, reporting them in an emergency action plan" in a way defined in the VIII attachment of the decree. Only companies up to 10 employees and with a low fire risk (as defined in the Ministry of the Internal Policies decree 16 February 1982 as: scarcely flammable substances; fire trigger poor possibility; fire propagation low probability) are excepted to get the emergency action plan, but aren't to carry out the emergency measures.

\subsection{The I.S.M.A. emergency action plan}

The I.S.M.A. emergency action plan states all the actions and coordinated set of behaviours to hold in the case of accidents that are potential or actual dangers for the health and safety of people or of the loss of goods.

If an emergency occurs, the total evacuation takes place toward the meeting point in front of the office building's main entrance (see Figure 1). The emergency team, made up by eleven members, executes orders from the appointed head of security, that is the Institute director or, if absent, the oldest official.

As soon as possible the members provide to:

$\checkmark$ stop heating and ventilations plants;

$\checkmark$ switch off input electric power, power supply generators and batteries (in the main electric panels of the two buildings);

$\checkmark$ activate and drive all the fire-fighting devices in the case of fire.

At the same time, the switchboard operator transmits the workplace attendances' list to the emergency team's members. Every day he gets the daily workplaces attendances at half past nine in the morning.

\section{The I.S.M.A. Safety Registration System}

\subsection{Introduction}

In order to get the current safety registration system safer and more reliable, many different systems have been considered:

$\checkmark$ magnetic or optic badges;

$\checkmark$ GPS identification;

$\checkmark$ active chip or passive chip (RFID) identification;

$\checkmark$ informatics system identification. 
After a qualitative and quantitative evaluation of every method, based on:

$\checkmark$ security, intended as possibility for the employee to not be identified;

$\checkmark$ global cost;

$\checkmark$ simplicity of use and maintenance;

$\checkmark$ identification speed;

$\checkmark$ reliability, intended as working security during the emergencies.

We have chosen the one with a minimum, but at the same time acceptable features: the informatics system identification.

\subsection{Safety registration system architecture}

The informatics system employs the I.S.M.A. personal computers network. It is composed by the workplace attendances database and software.

The database code is written in Microsoft Access and Visual Basic for Applications v. 2005, and allows for a replacement of the current registration system with the use of a touch screen placed in the main entrance. The database contains the employees' name and internet protocol address (IP address) of their personal computers and some other information, for example the mobile phone number.

To register one existing user, he simply has to check the blank square and push the "Presente" (present) button (see Figure 3).

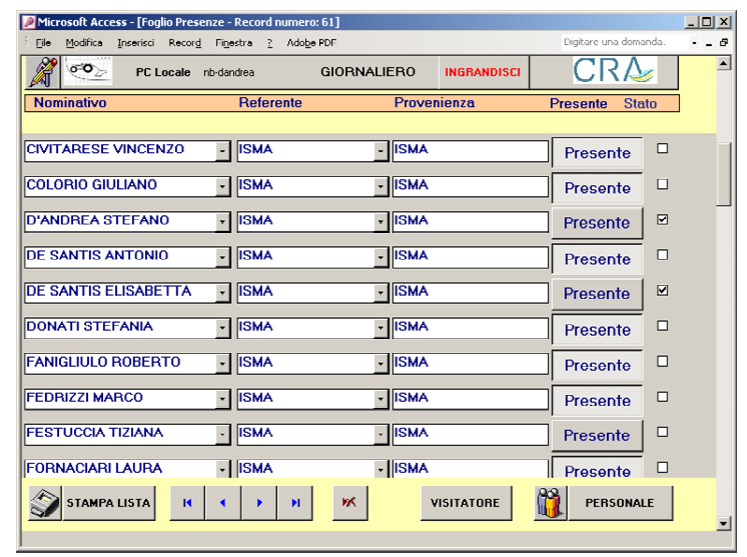

Figure 3: Safety registration system database's user interface. It is possible to get an updated printed list at any time.

To register a visitor, it is necessary to push the "Visitatore" (visitor) button and a form will appear (see Figure 4) where he/she can insert his/her name and the ISMA referring person name before pressing the "daily" button.

The software's operation to monitor the workplaces attendances is resumed in Figure 5. 
492 Safety and Security Engineering II

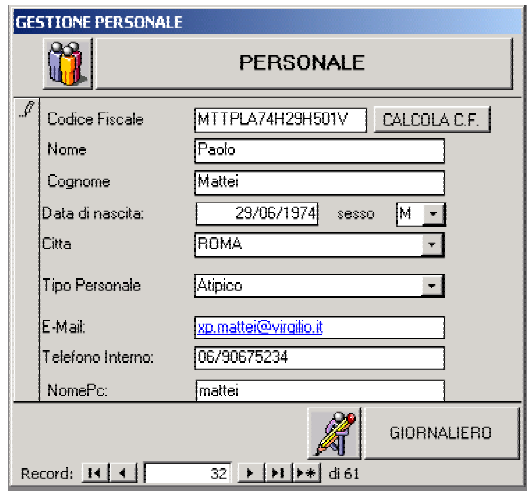

Figure 4: Database form for employees' management.

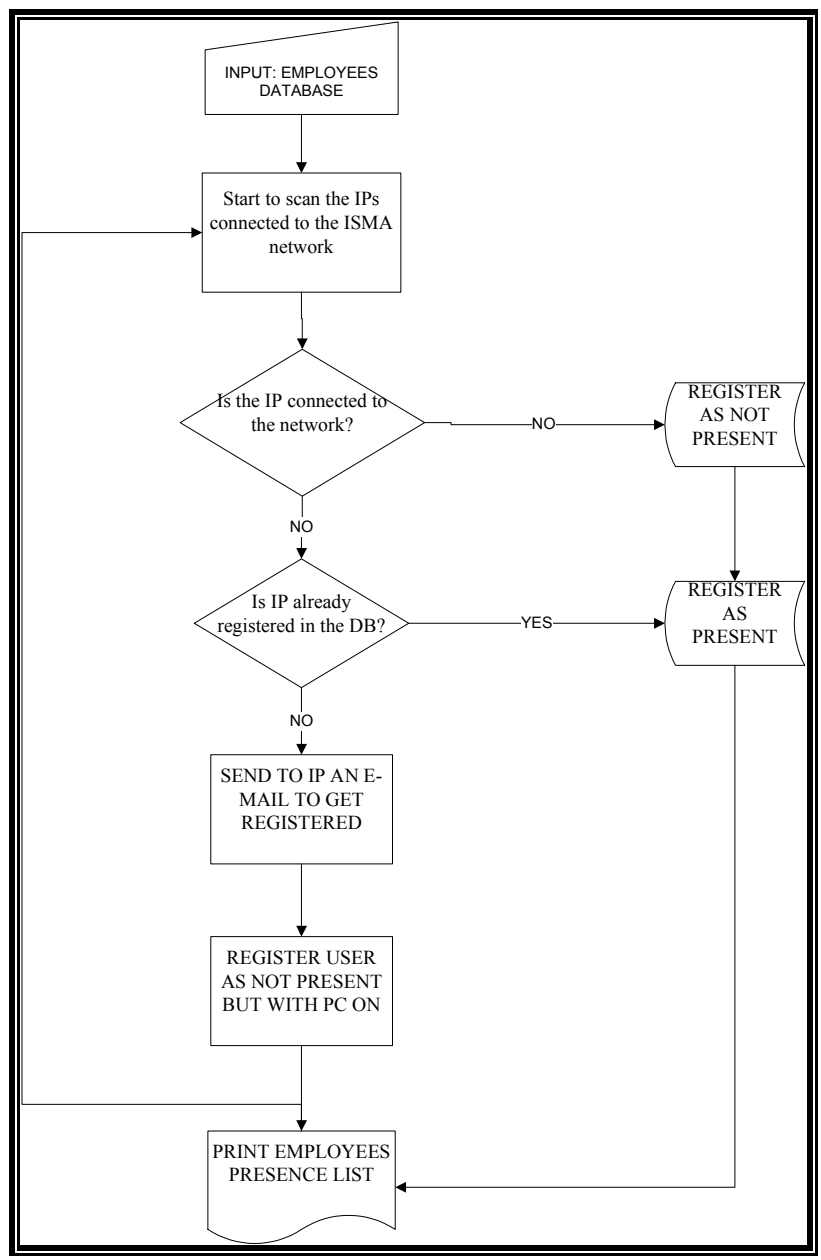

Figure 5: $\quad$ SRS software flowchart diagram. 
As we can observe the software scans the PCs connected to the network. Every PC has got static IP address, to which we can join only one user name. IP scan result can be one of the following cases:

a. employee connected to the network and registered;

b. employee connected to the network, but not registered;

c. employee not present.

For the second solution, the software sends to the IP an e-mail asking to get registered by means of a hyperlink to the executive program. Every time a PC connects to the network, this e-mail is sent.

To scan the PCs and to settle the user name, we use the Microsoft Windows API, while we employ Microsoft Winsock Object to send the e-mail.

The total time to scan the network is about two minutes. The checking PCs cycle is repeated continuously during the working daily hours.

The updated workplace attendances list is stored on two servers that are in the two main buildings. But the touch screen for the registration is located on the offices' building main entrance. This allows for increasing the availability of the SRS if fire destroys one of the two servers.

\subsection{SRS in action}

Whenever an emergency occurs, the switchboard operator prints out the updated workplace attendances list (see Figure 6) and transmit it to the aid team's members or to the emergency person in charge.

\begin{tabular}{|c|c|c|c|c|c|}
\hline Nominativo & Provenienza & Referente & Presente & Stato & Interno \\
\hline \multicolumn{6}{|c|}{ Impiegato } \\
\hline BENIGNI STEFANO & ISMA & ISMA & s! & $\otimes$ & $06 / 90675210$ \\
\hline BIOCCA MARCELLO & ISMA & ISMA & si & 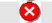 & 06,90675215 \\
\hline CEGNA MATTEO & ISMA & ISMA & sI & $\bar{\varnothing}$ & $06 / 90675264$ \\
\hline CERTELLI ELENA & ISMA & ISMA & sı & 凶 & $06 / 90675204$ \\
\hline DONATI STEFANIA & ISMA & ISMA & sl & 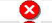 & 06,90675234 \\
\hline FANIGLIULO ROBERTO & ISMA & ISMA & sI & $\varnothing$ & $06 / 90675233$ \\
\hline FESTUCCIA TIZIANA & ISMA & ISMA & si & $\times$ & $06 / 90675207$ \\
\hline FORNACIARI LAURA & ISMA & ISMA & si & $\bar{x}$ & $06 / 90675256$ \\
\hline GALLUCCI FRANCESCO & ISMA & ISMA & s! & $\bar{x}$ & $06 / 90675238$ \\
\hline LUCARINI RENATA & ISMA & ISMA & si & 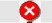 & 0660675228 \\
\hline MANCINI ANNAMARIA & ISMA & ISMA & si & $x$ & $06 / 90675203$ \\
\hline MATTEI PAOLO & ISMA & ISMA & si & $\times$ & $06 / 90675234$ \\
\hline MENESATTI PAOLO & ISMA & ISMA. & sl & (x) & $06 / 90875227-255$ \\
\hline NICIARELLI ILIANA & ISMA & ISMA & si & (x) & 06190675228 \\
\hline PANDOLFI VILMA & ISMA. & ISMA & sI & (x) & 06690675224 \\
\hline PANSINI LUIGI & ISMA & ISMA & si & $\otimes$ & $06 / 90675248$ \\
\hline POCHI DANIELE & ISMA & ISMA & si & $x$ & $06 / 90675232$ \\
\hline QUAGLIA ROBERTO & ISMA & ISMA & si & $\otimes$ & 06/90675246 \\
\hline RANIERI ALESSANDRA & ISMA & ISMA & SI & $x$ & $06 / 90675208$ \\
\hline SPERANDIO GIULIO & ISMA & $\sin A$ & si & $x$ & $06 / 90675218$ \\
\hline TOMASONE ROBERTO & ISMA & ISMA & s! & $\varnothing$ & $06 / 90875253$ \\
\hline VALERII MIRELLA & ISMA & ISMA & si & $\otimes$ & $06 / 90875206$ \\
\hline VASSALINI GENNARO & ISMA & ISMA & si & $\varnothing$ & $06 / 90675237$ \\
\hline BETTO MONICA & ISMA & ISMA & NO & $\theta$ & $06 / 90675242$ \\
\hline CIAMPAGLIA NADIA & ISMA & ISMA & NO & $\theta$ & $06 / 90675200$ \\
\hline CIVITARESE VINCENZO & ISMA & ISMA & NO & $\theta$ & $06 / 90675218$ \\
\hline COLORIO GIULIANO & ISMA & ISMA. & No & $\theta$ & $06 / 90675254$ \\
\hline D'ANDREA STEFANO & ISMA & ISMA & NO & $\theta$ & $06 / 90675268$ \\
\hline GRILLI RENATO & ISMA & ISMA & No & $\theta$ & $06 / 90675263$ \\
\hline IMPERI GIANCARLO & ISMA & ISMA & NO & $\theta$ & $06 / 90675217$ \\
\hline MONTANARI SANDRO & ISMA & ISMA & NO & $\theta$ & $06 / 90675251$ \\
\hline PARI LUIGI & ISMA & ISMA & NO & $\theta$ & $06 / 130675249-250$ \\
\hline PROPERZI DEBORAH & ISMA & ISMA & NO & $\theta$ & $06 \cdot 90675209$ \\
\hline SANTORO GIOVANNI & ISMA & ISMA & NO & $\ominus$ & $06 / 90675240$ \\
\hline SERVADIO PIERANNA & ISMA & ISMA & No & $\theta$ & $06 / 90675221$ \\
\hline COSTA CORRADO & ISMA & ISMA & NO & 88 & $06 / 90875214$ \\
\hline GIULIANI VINCENZO & ISMA & ISMA. & NO & 89 & $06 / 90675258$ \\
\hline PALLOTTINO FEDERICO & ISMA & ISMA & NO & 88 & $06 / 90675214$ \\
\hline
\end{tabular}

Figure 6: Example of a printed workplaces attendances list. 
The employees list is ordered in a way of importance for the safety of people: the first group (labelled with a red circle and a white cross) is represented by people that are present and registered, then their presence on the meeting location needs fast identification; the second group (labelled with a orange circle) is represented by people with the PCs connected to the network, but not registered; another group is represented by users that are no more present in the network and the last group are the employees that are absent.

\section{Results}

Two evacuation exercises have taken place using the SRS. The ISMA emergency alarms have played. They are placed in:

$\checkmark$ offices' building ground floor;

$\checkmark$ offices' building first floor;

$\checkmark$ laboratories' building;

$\checkmark$ some experimental fields.

The escape routes from the buildings are about 35 meters long and there are three emergency exits in the building offices and 7 emergency exits in the laboratories' building.

The evacuation time is defined as the necessary time to left the building in safety and its time length is made up by some partial times:

1) perception and reaction time (called "milling" time);

2) recognition and action time.

In both trials, measured evacuation time was 2 minutes and 30 seconds and it is within limits imposed by the national occupational health and safety law (3 minutes for medium fire risk workplaces).

The major successful result of the SRS is the reduction of the time for reckoning employees to 3 minutes. By the previous method it was about 6 minutes.

\section{Problems and possible solutions}

During the first experimental stage of the safety registration system, its main limit is the percentage of employees that use it (see below Figure 7 the percentage of users that don't use the SRS is the $19 \%$ of 50 employees). This is due to the firm but false belief that the registration is not in the least useful and that people don't get registered out of carelessness. Indeed, the SRS is not mandatory, but we hope to get it mandatory by an internal provision of the I.S.M.A. director.

Another technical problem is that PCs that use some Firewall or Antivirus software aren't catchable by the scan process. A possible solution to this problem is to protect PCs with security software compatible with the scan software.

Another occurrence that can bring about some problems is the temporary absence of some employees (for experimental tests or for some hours' leave). In this case it is sufficient to disconnect the PC from the network. 


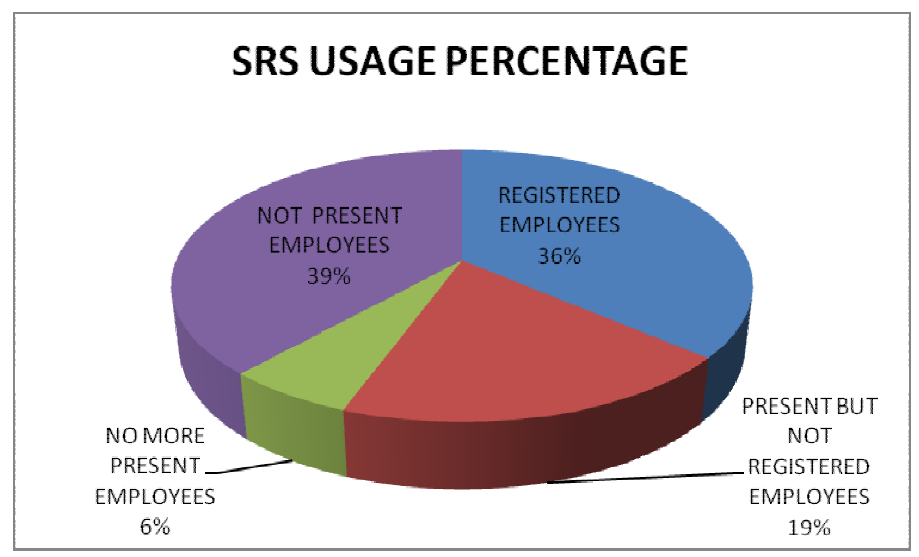

Figure 7: $\quad$ SRS usage percentage.

A difficulty can rise to respect the employees' privacy. One possible solution is to permanently delete the previous day attendances from the two servers.

Some enhancements are being considered.

$\checkmark$ To check the registered employees in a cross way with the employees on vacation. This could be made by the personal office that daily updates the vacation employees list in electronic format. Then the software can hold this list to elaborate a more precise workplace attendances roll.

$\checkmark$ To connect the printing operation to the alarm signal.

$\checkmark$ To draw a matrix on the meeting location where people of one sector of the building have their name written down.

\section{Summary and conclusions so far}

We have run two trials using the newly projected Safety Registration System. Both of them have shown that the SRS is certainly safer as it lessens the risk of losing the attendance list; secondly it is more reliable than the previous method because the SRS software warns every previously unregistered worker to sign in. Thirdly it is a cost-effective way to try to solve the huge problem of emergency's roll-call within short time.

In spite of there being situations that need further enhancements (for example employees involved in tests far away from their usual location), the SRS allows for a reduction of the aid time to the missing people up to the $100 \%$ because the emergency team can focus researches and aid only in specific areas.

To sum up, we can surely state that the testing results have shown that ISMA's SRS highly improves execution of safety emergency procedures.

\section{References}

[1] Hubert Klupfel a Tim Meyer-Konig b Michael Schreckenberg, Empirical data on an evacuation exercise in a movie theatre, Fire Safety Journal, 2001. 
496 Safety and Security Engineering II

[2] OSHA fact sheet, Emergency exit routes, 2003.

[3] Dirk Helbing, Illeâs Farkas \& Tamâs Vicsek, Simulating dynamical features of escape panic, Nature, Vol. 407, pp. 487-490, 2000.

[4] Luca Pierantoni, Gabriele Prati, Il comportamento umano negli incendi, Obiettivo Sicurezza - Rivista ufficiale del Corpo Nazionale dei Vigili del Fuoco, pp. 53-57, Marzo 2007. 